Iriani., Muniarty, P.

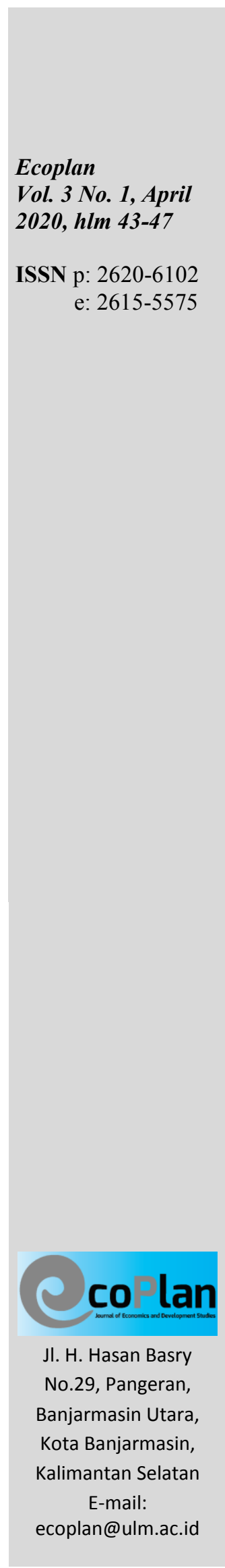

\title{
ANALISIS PENGARUH STRUKTUR MODAL TERHADAP PENDAPATAN PERUSAHAAN PADA PT BANK BNI SYARI'AH, TBK
}

\author{
Iriani, Puji Muniarty* \\ Program Studi Manajemen, Sekolah Tinggi Ilmu Ekonomi Bima \\ *E-mail corresponding author: puji.stiebima@gmail.com
}

Abstract - A bank is one of financial institutions. To carry out its operations, the bank needs to provide a lot of capital so that it does not experience the financial difficulties. The authors found out that the weak structure of banking capital is one of the reasons why the banks can't defend themselves from losses incurred. The banking risk can be seen from the unoptimized management of capital structure and income. This study aims to analyze the effect of capital structure on the company's income in PT Bank BNI Syari'ah, Tbk. The population used in this study is the data ranged from 2009 to 2018 with a total sample of 7 years from 2012 to 2018. The type of research is associative research by using simple linear regression analysis with smallest squared Method (Ordinary Least Square). The conclusion is the capital structure does not affect significantly on the company's income of PT. Bank BNI Syari'ah, Tbk.

Keywords: Capital Structure, Income, Sharia Bank

\section{THE EFEECT OF CAPITAL STRUCTURE ON THE COMPANY'S INCOME IN PT BANK BNI SYARI'AH, TBK}

Abstrak - Bank merupakan suatu lembaga keuangan, untuk melakukan operasinya bank perlu menyediakan modal yang banyak agar tidak berada pada kesulitan keuangan. Maka penulis melihat tidak konstanya struktur modal perbankan dalam menghadapi kerugian. Resiko perbankan dapat terlihat dari tidak optimalnya dalam pengelolaan struktur modal dan pendapatannya. Adapun tujuan penelitian untuk menganalsis pengaruh struktur modal terhadap pendapatan PT Bank BNI Syari'ah, Tbk. Populasi penelitian yaitu 2009-2018 dengan jumlah sampel 7 tahun periode tahun 2012-2018. Jenis penelitian termasuk asosiatif dengan analisa regresi, koefisien korelasi dengan metode kuadrat terkecil. Kesimpulan Penelitian struktur modal tidak berpengaruh dan tidak signifikan terhadap pendapatan pada PT. Bank BNI Syari'ah, Tbk.

Kata Kunci : Struktur Modal, Pendapatan, Bank Syariah 


\section{PENDAHULUAN}

Persaingan bisnis lembaga perbankan sebagai jasa keuangan sangat ketat. Hal itu terlihat dari beberapa strategi marketing yang dijalankan oleh pihak bank dalam mencapai keuntungan. Oleh sebab itu peranan lembaga keuangan untuk kemajuan perekonomian termasuk instansi instansi maupun usahan kecil sangat membutuhkan suatu dana untuk menjalankan kegiatannya. Adapun peran penting perbankan itu sendiri yaitu untuk menyalurkan dana kepada yang membutuhkan serta menjalankan fungsi bank tersebut dan bisa menjaga kondisi yang baik dengan cara mengoptimalisasikan struktur modal bank itu sendiri oleh karena itu diperlukan system perbankan yang sehat (tidak bermasalah) sebgai prasyarat terciptanya perekonomian yang baik.

Tugas dari bank itu sendiri merupakan aspek penghimpun dan penyaluran dana, untuk menjalankan fungsinya bank tersebut harus menjaga kondisi yang baik dengan cara mengoptimalkan struktur modal bank itu sendiri.

Penggunaan struktur modal yang efisien dan efektif menunjukkan bahwa kinerja perusanaan itu berada pada posisi yang baik. Pengunaan struktur modal dengan beban hutang yang tinggi berdampak pada biaya yang tinggi menyebabkan tingginya resiko koorporasi sehingga akan terjadi tidak terbayarnya bunga, Hanafi (2014). Variabel bebas diproksikan dengan penggunaan rasio DER yaitu membandingkan hutang dan modal sendiri oleh perusahaan. Berdasarkan data yang di peroleh dari data laporan keungan pada PT. BNI Syari'ah yaitu struktur modal serta pendapatannya mengalami kondisi yang fluktuatif, kondisi struktur modal akan berkaitan langsung terhadap kondisi keungan perushaan sehingga mempengaruhi kinerja perusahaan sedangkan pendapatan akan mempengaruhi tingkat kesejahteraan anggota perusahaan. Adapun data empirik struktur modal dan hubungannya dengan pendapatan PT. BNI Syari'ah, Tbk sebagai berikut :
Tabel 1 Struktur Modal dan Pendapatan Tahun 2012 - 2018

\begin{tabular}{ccc}
\hline & & \\
Tahun & $\begin{array}{c}\text { Struktur Modal } \\
(\mathrm{X})\end{array}$ & $\begin{array}{c}\text { Pendapatan } \\
(\mathrm{Y})\end{array}$ \\
& & \\
\hline 2012 & 1.84 & 10.79 \\
2013 & 2.94 & 11.29 \\
2014 & 1.58 & 11.26 \\
2015 & 1.49 & 11.10 \\
2016 & 1.88 & 11.07 \\
2017 & 1.74 & 10.95 \\
2018 & 2.31 & 9.41 \\
\hline
\end{tabular}

Sumber data : PT. BNI Syari’ah, Tbk 2020

Berdasarkan tabel 1 di tarik sebuah kesimpulan bahwa struktur modal serta pendapatan PT. BNI Syari'ah Tbk menunjukkan kondisi yang fluktuatif, dimana pada tabel di atas peningkatan strukur modal terjadi pada tahun 2018 sebesar $2.31 \%$ dan pendapatan mengalami penurunan di tahun yang sama yaitu 9.41 dibandingkan tahun 2017 sebesar 10.95. Hal tersebut disebakan oleh hutang pada PT. Bank BNI Syari'ah, Tbk mengalami kenaikan yang signifikan. Permasalahan dalam penelitian yaitu apakah terdapat pengaruh yang signifikan struktur modal terhadap pendapatan pada PT. Bank BNI Syari'ah, Tbk, dengan tujuan penelitian untuk mengetahui ada tidaknya pengaruh yang signifikan struktur modal terhadap pendapatan pada PT. Bank BNI Syari'ah, Tbk.

Pentingnya struktur modal dalam penyelesaian unit usaha perusahaan maka perusahaan perlu memperhatikan struktur modal. Alasannya karena struktur modal berpengaruh tehadap pendapatan yang akan dicapai oleh perusahaan sehingga dapat memudahkan perusahaan dalam menganalisis pengaruh penggunaan utang terhadap tingkat pendapatan agar dapat dijadikan sebagai alat pengambilan keputusan keuangan.

\section{TINJAUAN PUSTAKA}

\section{Struktur Modal}

Struktur modal merupakan panduan sumber dana jangka panjang yang digunakan oleh perusahaan (Keown 2000).Hubungan antara struktur keuangan dan modal dapat di nyatakan dalam bentuk (strukur keuangan)-(kewajiban 
lancer $)=$ struktur modal. Pada umumnya struktur modal di fokuskan pada proporsi antara hutang (debt) dengan modal (equity) yang dilihat pada sisi kanan neraca perusahaan.

Menurut Sulistiono (2010:26) struktur modal yaitu membandingkan liabilitas dengan equity Bagian-bagian Struktur modal yaitu utang jangka panjang dan modal sendiri. Termasuk utang jangka panjang yaitu hutang obligasi, hutang hipotik, utang sewa guna usaha. Contoh modal sendiri yaitu laba di tahan, saham biasa, saham preferen.

DER digunakan untuk mengukur struktur modal PT Bank BNI Syari'ah, Tbk. Perusahaan yang memiliki total kewajiban yang tinggi dibandingkan capital perbankan menunjukkan tingkat resiko yang besar pada lembaga perbankan. Semakin tinggi hutang akan menurunkan beban bunga dan nilai perusahaan. Houston, (2015) dihitung dengan :

$$
\text { DER }=\frac{\text { Total Hutang }}{\text { Total Ekuitas }} \times 100 \%
$$

Nilai DER dibawah angka 1 atau kurang dari $100 \%$ berarti perusahaan masuk kategori sehat.

\section{Pendapatan}

Lumbantoruan dan Magdalena (2011:236) bahwa pendapatan adalah selisih antara laba dan biaya". Investor akan melakukan investasi dengan meninjau pendapatan perbankan dipasar modal untuk menentukan pilihannya dalam menanamkan investasi sahamnya. Berdasarkan defenisi dapat disimpulkan bahwa pendapatan merupakan penghasilan perusahaan yang diukur berdasarkan selisih total biaya.

Pada bank syari'ah pengukuran pendapatan dilakukan setelah pembahagian hasil dan tidak dapat diketahui ketika transaksi berlangsung. Pendapatan dalam penelitian ini mengambil salah satu pendapatan yaitu pendapatan ijarah sesuai dengan syariat islam. Pendapatan ijarah merupakan pendapatan yang diperoleh selama masa akad diakui atau pada saat aset ijarah telah diserahkan kepada penyewa (nasabah).

Pendapatan lain yang diperoleh oleh PT. Bank BNI Syariah adalah pendapatan ijarah yaitu menyewa suatu tanpa maksud memilikinya dengan menglogaritma naturalkan nilai pendapatan yang ada.

\section{METODE PENELITIAN}

Lokasi Penelitian PT. Bank BNI Syariah, Tbk. yang beralamat di : Gedung Tempo Pavilion I Jln. HR Rasuna Said Kav 10-11 lanta 3-6
Jakarat 12950 Indonesia melayu website resmi www.bnisyariah.co.id dengan rentang waktu penelitian selama 3 (tiga) bulan yaitu bulan november 2019 sampai bulan januari 2020. Jenis penelitian yang digunakan oleh penulis adalah asosiatif dengan populasi dalam penelitian ini adalah laporan keuangan neraca terdiri atas total liabilitas, total ekuitas dan laporan laba rugi terdiri atas pendapatan ijarah pada PT. Bank BNI Syariah, tahun 1999-2018. Sampel penelitian yaitu 7 tahun yaitu tahun 2012-2018. Jenis data yang digunakan dalam penelitian ini yaitu data time series dengan data yang di gunakan dalam penelitian ini yaitu selama 7 tahun sesuai sampel dalam penelitian ini.

\section{Teknik pengumpulan data}

Teknik pengumpulan data yang dilakukan peneliti dalam penelitian ini yaitu : (1) studi pustaka merupakan suatu kegiatan yang harus dilakukan dalam suatu penelitian karena mencakum teori-teori yang mendasari permasalahan yang akan diteliti dan dapat diketahui melalui kegiatan studi pustaka (2) dokumentasi merupakan kegiatan yang dilakukan untuk mendapatkan informasi dari buku, majalah, surat kabar dan lain sebagiannya untuk dijadikan bukti yang akurat.

\section{Teknik analisis data}

Teknik analisis data yang digunakan dalam penelitian ini yaitu regresi linier sederhana dengan metode kuadrat terkecil yaitu untuk mencari forecasting secara liniear antara variabel struktur modal (X) dengan variabel pendapatan (Y). Rumus persamaan regresi liniear sederhana yaitu sebagai berikut:

$$
Y=a+b X
$$

Keterangan:

$\mathrm{Y}=$ Strukrur Modal

$\mathrm{X}=$ Pendapatan

$\mathrm{a}=$ konstanta regresi

$\mathrm{b}=$ koefisien regresi 
HASIL DAN PEMBAHASAN

Analisis regresi liniear sederhana

Tabel 2 Coefficients

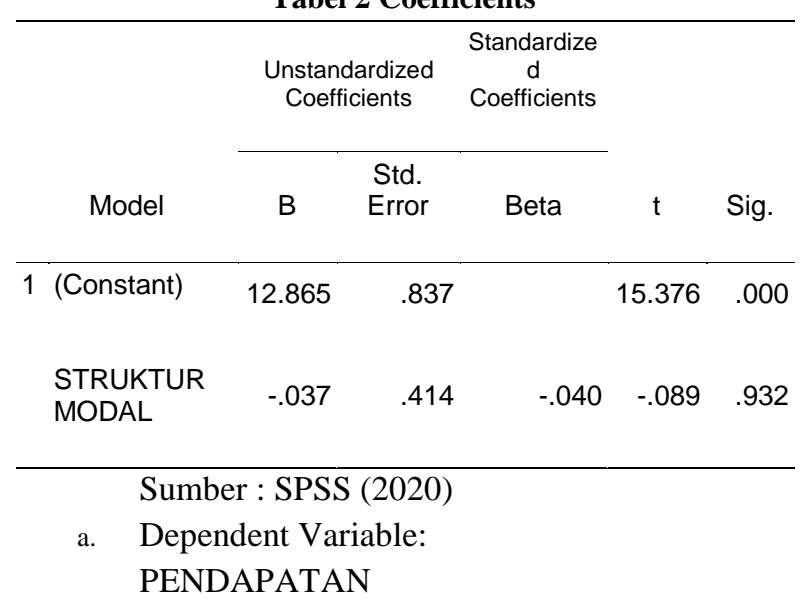

Persamaan garis linier sederhana dari hasil output pengolahan data dari tabel 1 yaitu : $\mathrm{Y}=12,865$ 0,037X.

\section{Koefisien korelasi sederhana}

Tabel 3 Model Summary

\begin{tabular}{lllll}
\hline & & & & \multicolumn{2}{l}{ Std. Error } \\
Model & $\mathrm{R}$ & $\mathrm{R}$ & Adjusted & of the \\
Square & R Square & Estimate \\
\hline 1 & $.040^{\mathrm{a}}$ & .002 & -.198 & .50945 \\
\hline
\end{tabular}

a. Predictors: (Constant),

STRUKTUR MODAL

Hasil output data dengan SPSS menunjukkan nilai korelasi yaitu 0,040 bermakna tingkat keeratan hubungan variabel struktur modal (X) dengan variabel pendapatan (Y) berada pada tingkat hubungan yang lemah.

\section{Koefisien Determinasi Sederhana}

Tabel 3 menunjukkan angka $\mathrm{R}^{2}$ diperoleh $0,002(0,2 \%)$ menunjukan bahwa variabel struktur modal hanya mampu berkontribusi terhadap pendapatan PT. Bank BNI Syari'ah, Tbk, sedangkan sisanya 0,998 atau $99,80 \%$ dipengaruhi oleh faktor cateribus paribus.
Uji t

Tabel 4 Coefficients

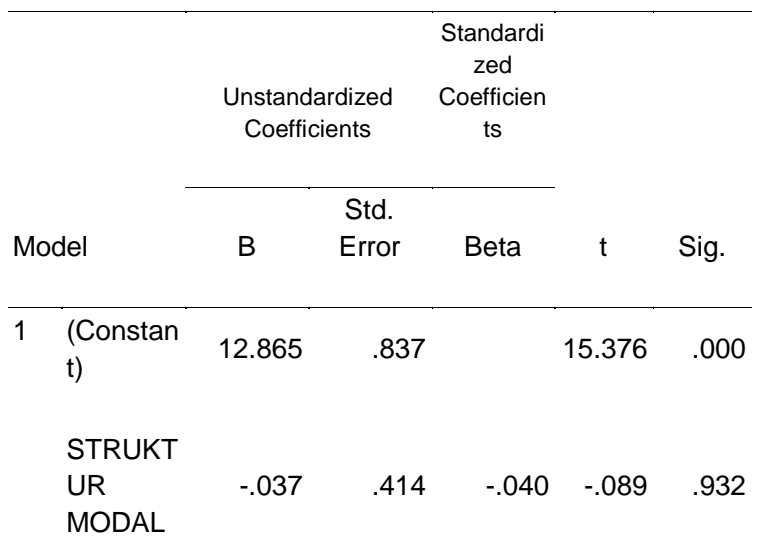

Sumber : SPSS (2020)

a. Dependent Variable:

PENDAPATAN

Nilai $t_{h}$ pada tabel di atas kurang dari $t_{t}(-$ 0,089 lebih kecil 2,045 ) dengan tingkat signifikan sebesar 0,932>0,05, bahwa struktur modal tidak ada pengaruh dan tidak signifikan terhadap pendapatan PT. Bank BNI Syari'ah, Tbk, dengan kata lain Penggunaan utang yang tinggi memiliki resiko yang tinggi yaitu adanya beban bunga yang tinggi. Perusahaan harus berhati-hati dalam menggunakan utang dalam struktur modalnya, karena sampai saat ini tidak ada model matematik yang pasti tentang komposisi struktur modal yang optimal dalam perusahaan. Struktur modal yang optimal dapat meningkatkan pendapatan perusahaan, sehingga nilai saham perusahaan juga akan ikut meningkat seiring dengan pencapaian pendapatan perusahaan. Bistrova, Lace dan Peleckiene (2011) dalam penelitian nya terhadap 36 perusahaan blue chip yang listing di Baltic Stock Exchange menyatakan tidak terdapat pengaruh antara struktur modal dan pendapatan perusahaan, selain itu ditemukan hubungan terbalik antara tingkat utang dan keuntungan modal sesuai pecking order theory bahwa dalam kasus terbaik perusahaan sebaiknya menggunakan dana internal.

\section{KESIMPULAN DAN SARAN}

\section{Kesimpulan}

Berdasarkan hasil penelitian yang dapat penulis lakukan yaitu :

1. Tidak ada pengaruh dan tidak signifikan antara Struktur modal terhadap pendapatan PT. Bank BNI Syari’ah, Tbk. 
2. Penulis berharap kepada pihak PT. Bank Syari'ah, Tbk., agar pengelolaan keuangan kedepannya lebih baik sehingga perusahaan perbankan akan lebih Eksis lagi dalam Saran bersaingan ke dunia bisnis.

1. Adapun saran yang dapat penulis sampaikan bahwa PT Bank Syariah, Tbk harus memperhatikan cashflor cost dan income perbankan sehingga pendapatan perusahaan meningkat.

2. Perusahan harus pintar - pintar dalam menilai perbandingan bahwa hutang dengan modal sendiri akan mengoptimalisasi perusahaan tersebut.

3. Penulis berharap pada PT. Bank BNI Syari'ah. Tbk, bisa menjaga kemitraan dengan lembaga - lembaga keuangan yang ada di seluruh dunia maupun di wilayah Indonesia supaya kedepannya dalam pengelolaan keuangan akan lebih baik lagi.

\section{DAFTAR PUSTAKA}

Bistrova, Julia, Lace, Natalja and Peleckiene, V. 2011, The influence of capital structure on Baltic corporate performance, Journal of Business Economics and Management, 12:4, 655669

Brigham, Eugene F. dan Joel F. Houston. 2015. Dasar-Dasar Manajemen Keuangan.
Buku 1. Edisi 12. Jakarta : Salemba Empat.

Dantes, Nyoman. 2012. Metode Penelitian. Yogyakarta: Andi

Fitriyanto, 2018. Pengaruh Struktur Modal dan

Faktor Eksternal terhadap Nilai Perusahaan (Studi pada PT. Bank Central Asia, Tbk). Jurnal Manajemen Dan Keuangan, Vol.7, No.1, Mei 2018

Ismail. 2014. Perbankan Syariah. Jakarta: Kencana Prenadamedia Group

Lumbantoruan, Magdalena, 2011. Ensiklopedia Ekonomi, Bisnis, dan Manajemen. Jakarta: PT Delta Pamungkas

Mamduh, M. Hanafi, 2014. Analisis Laporan Keuangan. Edisi Keempat. Yokyakarta: UPP STIM YKPN.

Suad, Husnan, 2014. Manajemen Keuangan Edisi Keempat. Yogyakarta : BPFE

Zaki, Baridwan. 2010. Sistem Akuntansi Penyusunan Prosedur dan Metode. Edisi 5. Yogyakarta : BPPE 